\title{
Some aspects of hydraulic education in agricultural engineering in Czechoslovakia
}

\author{
P. Kovar \\ University of Agriculture, Prague
}

\section{Introduction}

A complex solution of water resources tasks being connected with land reclamation problems on the catchment undoubtedly require a team cooperation. Such a team of specialists on the level of consulting body should negotiate and then decide the optimum solution concerning to water supply, drainage, water erosion, water pollution problems, etc. The sensitive interrelations between agriculture and water resources are known.

The substantial part of small water-courses, reservoirs, all irrigation and drainage systems are managed and operated by agricultural authorities in Czechoslovakia. This situation has raised the need to establish the Land and Water Engineering Branch at the University of Agriculture, Prague in 1960. The main tasks of the Branch have been preferably put in preparing specialists who are supposed to do a water-service for higher intensification of agricultural production. Endeavouring to be selfsufficient in a foodstuffs production the country including their natural water sources has been more and more devastated. Being fully aware of this process we tried to draw attention of responsible authorities that almost one third of arable land has been exposured by water erosion, furthermore that overfertilization causes contamination of a soil-water environment, water eutrophication, etc...

Nowadays, Czechoslovakia which comes back to Europe is being faced these problems. Their solution needs high requirements in qualification of our students. Therefore the curricula and syllabi formulating the teaching programme of the Land and Water Engineering have been recently drastically changed in favour of environmental engineering with the aim to educate people who could:

- to solve the feedback between agricultural production and corresponding land exploitation to keep both phenomena in equilibrium,

- to look after water resources on agricultural catchments with the aim of rational water use and of decrease a surface runoff,

- to take care of existing water resources and hydraulics structures and facilities,

- to be able to evaluate a specific situation and then to take measures including the design of new facilities being in a good production-environmental balance.

From these requirements follows the outlines for a new teaching programme which should start in the Academic Year 1990/91.

\section{The teaching programme}

The main idea of water resources education at the University of Agriculture, Prague is that hydrology and hydraulics are treated as a part of environmental engineering. We

\section{Quelques aspects de la formation en hydraulique des ingénieurs agronomes en Tchécoslovaquie}

La communication décrit les études de futurs ingénieurs agronomes et les cours postuniversitaires organisés pour des hydrologues à l'Ecole supérieure d'agriculture : cours d'hydrologie et d'hydraulique axés sur l'étude de l'écoulement dans les bassins de fleuves et rivières, compte tenu de l'action des hommes; cours postuniversitaire de six mois sur l'hydrologie; formation des participants venant des pays du tiers monde. 
are firmly convinced that these subjects which create the important component of a natural environment ought to be taken into consideration together with other environmental components.

The Branch of Land and Water Engineering consists of four departments :

Department of Land Reclamation.

Department of Water Resources.

Department of Civil Engineering.

Department of Environmental Protection.

The five year study (10 semesters) lead to MSc degree in Land and Water Engineering. The courses listed below are treated as almost obligatory for first two years, later the proportion between obligatory subjects and facultative ones comes more to the benefit of free choice respecting the proposed combination of them. All lectures are facultative while the other forms of teaching process (exercises, seminars, laboratory and field works, projects) are compulsory. The Study Programme is listed in the Table.

During practical exercises students will be offered a number of numerical examples and case studies providing an illustration to the relevant lectures. Other part of exercises is intended primarily for the student's own work with the aid of professor assistants.

\section{Problems in teaching hydraulics and hydrology}

Both hydraulics and hydrology are the subjects of the theory application. Therefore there undoubtedly require a good background in mathematics and physics. From that follows the first short-coming in a teaching-learning process. In particular, for modern hydraulics the good knowledge of numerical transfer of partial differential equations to the difference equations system is a prerequisite. Traditional analytical solutions (if ever exists) which are still emphasized in a classical mathematics are being more overshadowed by the numerical methods. Not all mathematicians realize the increasing need for the numerical methods promotion as a necessary tool for a computational hydraulics.

On the other hand, regardless the form rooting of hydraulics with operational mathematics, the educational programme should not become so entranced with computational technique that the nature of the problem is forgotten.

In my opinion, hydrology and hydraulics should be tought next to each other to provide as complete coverage of the matter as possible. Particularly, unsteady flow problems give a good example in the form of mathematical models based physically, i.e. hydraulic models or hydrological models which are also known as conceptual ones. These models should be tackled simultaneously with particular reference to their advantages and/or shortcomings in both courses: hydrology as well as in hydraulics regardless a possible overlapping. Such courses might be undertaken only by joint teaching team comprising selected lectures to present topics from their particular area of specialization.

Concerning specific problems in education in Czechoslovakia there were also shortcomings from the old system :

- Unsufficient cooperation with other Universities in Europe.

- Lack of financial subsidence namely for laboratories and for a field practice.

- Low study motivation.

Now, the International University Programmes like COMET, ERASMUS, TEMPUS, etc... introduce good possibilities for cooperation. Anyhow, there is no doubt the presented programme will be subjected to continous evaluation following the overall advances of the water related disciplines.

\section{Postgraduate study}

The long tradition as well as the number of specialists in teaching hydrology and hydraulics in Prague have enabled to held the Postgraduate Courses sponsored by UNESCO since 1966. Professional orientation follows from the title : "Hydrological Data for Water Resources Planning ». The teaching situation in the Courses differs from the situation in the graduate study. Owing to the collaboration with UNESCO itself and with some other European UNESCO sponsored postgraduate Courses there is a good experience in organizing and teaching activities. Our Courses are organised bianually (every second year) and they last six months. The 13th Course has been just finished in July 1990. Looking back there have been more than 180 alumnies from 25 countries who passed through the Course. The Course curricula consists of 24 subjects to be taught there. The curricula and syllabi are given in the Course brochure.

The major teaching problems in the Course can be listed as follows :

- Large scatter of previous knowledge in water sciences which cannot be tested before the Candidate's acceptance.

- Reassuming of lectures and exercises to create a logical succession which could be acceptable to all student's with different theoretical background.

- Many individual trainees from developing countries get used to put emphasis more to the technical aspects than to ecological ones when making decision on a hydraulics structure. Trends to environmental protection are often underestimated.

One may conclude in general that scientific advances in hydrology and hydraulics provide powerful tools for analysis of any complex situation. On the other hand, the student must realize that all water resources problems have not only a natural character but are also influenced by economic and social factors which make problems more difficult and which should be certainly taken into consideration, too. 
THE TEACHING PROGRAMME 1990/91

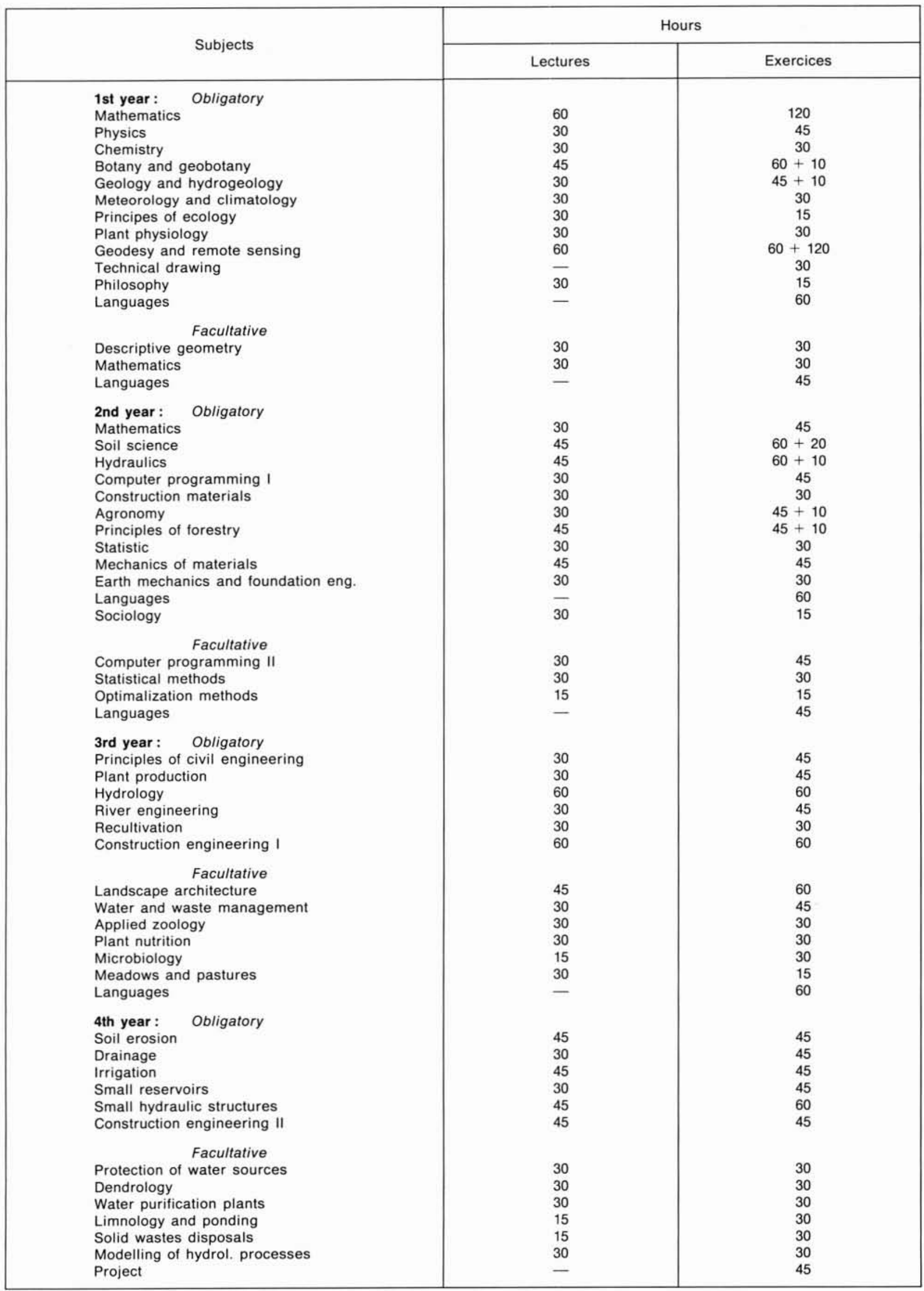




\begin{tabular}{|l|c|c|}
\hline Diploma seminar & - & 30 \\
5th year: Obligatory & & \\
Organization of land use and mana- & & 30 \\
gement & 30 & 45 \\
Torrent erosion control & 30 & 35 \\
Environmental protection & 30 & 30 \\
Water resources systems & 30 & 30 \\
$\quad$ Facultative & & 30 \\
Rural road network & 30 & 30 \\
Remote sensing & 30 & 30 \\
Exploitation of reclamation structures & 30 & 45 \\
Economics & 30 & 30 \\
Law & 30 & 30 \\
Regional planning & - & - \\
Diploct seminar & & \\
\hline
\end{tabular}

